\title{
0 médico-veterinário e a dengue: sua crescente $e$ atual interface
}

\section{The veterinarian and dengue: its growing and current interface}

\section{Resumo}

A dengue é uma importante arbovirose que afeta o ser humano e constitui sério problema de saúde pública no mundo. Sob esse ponto de vista, essa enfermidade sistêmica viral é também uma preocupação dos médicos-veterinários. O objetivo do presente trabalho foi investigar as bases e origens dessa relação entre a Medicina Veterinária e as arboviroses, como a dengue. Infere-se que, em primeiro lugar, o poder de ação dos médicos-veterinários engloba a monitoração e análise dos indicadores epidemiológicos. Em um segundo momento, conclui-se que os médicos-veterinários, vinculados ou não ao Programa Nacional de Controle da Dengue (PNCD), têm uma importante responsabilidade na geração de propostas de prevenção da dengue, chikungunya e zika.

\section{Summary}

Dengue is one of the most important arboviral diseases that affect humans and is a serious public health problem in the world. From this point of view, this viral systemic disease is also a concern for veterinarians. The objective of this study was to investigate the fundamentals and origins of the relationship between veterinary medicine and arboviral diseases such as dengue. It is first inferred that the power of influence of veterinarians encompasses monitoring and analysis of epidemiological indicators. Additionally, it is concluded that veterinarians, whether linked or not to the Dengue Control Program (DCP), have an important responsibility in generating prevention proposals against dengue, chikungunya, and zika. 


\section{Palavras-chave}

Médico-veterinário. Dengue. Ação preventiva.

\section{Keywords}

Veterinarian. Dengue. Preventive actions.

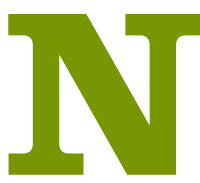

a atualidade, medidas informativas trazem com frequência a dengue, uma infecção sistêmica viral, como foco a ser abordado para o conhecimento de toda a população nacional. Participante dos principais tabloides e mídias televisionada e on-line, a doença, transmitida pelo mosquito Aedes aegypti, é famosa pelas constantes notificações e previsões médicas nada otimistas quanto à sua prevenção e erradicação.

A Organização Mundial da Saúde (OMS) estima que 80 milhões de pessoas se infectem anualmente, em cem países, exceto na Europa, com a dengue (DAHER et al., 2013). Para essa doença não há tratamento etiológico e quimioprofilaxia efetiva e, tampouco, uma vacina acessível. A enfermidade é reemergente e tem a maior taxa de incidência mundial. O Brasil é líder em casuística, logo abaixo de países asiáticos como Índia, Java e Indonésia, e países africanos como Sudão, Tanzânia, Mali e Quênia (BHATT et al., 2013). O boletim epidemiológico divulgado pelo Ministério da Saúde revela que, somente nos quatro primeiros meses deste ano, foram registrados 1.054 .127 casos prováveis de dengue no Brasil (MATOS, 2016).

A quantidade de casos continua preocupando as autoridades em Medicina Preventiva e saúde pública de todo o mundo. O México, o Haiti e a Venezuela também apresentam alta ocorrência devido à temperatura de clima tropical, à umidade relativa do ar e à precipitação. O perfil bioclimático faz com que esses países tenham a tendência de expressar alta casuística para a dengue, assim como o Brasil.

A associação entre o clima e a doença é objeto de estudo da geografia médica, termo introduzido por Samuel Barnsley Pessoa, em 1960, 
que leva em consideração a saúde e a superfície da Terra (SANTOS, 2010). De acordo com Pessoa (1960), “[...] a Geografia Médica tem por fim o estudo da distribuição e da prevalência das doenças na superfície da Terra, bem como de todas as modificações que nelas possam advir por influência dos mais variados fatores geográficos e humanos". Ainda sobre esses conceitos, Lacaz, Baruzzi e Siqueira Júnior (1972) dizem que: “[...] sob o ângulo da Geografia Médica, devemos considerar, ao lado do agente etiológico, do vetor, do reservatório, do hospedeiro intermediário e do Homem susceptível, os fatores geográficos representados pelos fatores físicos (clima, relevo, solos e hidrografia) fatores humanos ou sociais (distribuição e densidade da população, padrão de vida, costumes religiosos e superstições, meios de comunicação) e os fatores biológicos (vidas vegetal e animal, parasitismo humano e animal, doenças predominantes, grupo sanguíneo da população etc.).

No Brasil, os fatores geográficos que interferem no ciclo de vida do Aedes aegypti propiciam a expansão da dengue, por meio das condições favoráveis para o desenvolvimento do vetor. A proliferação dos mosquitos surge acompanhando o crescimento das cidades, em virtude das condições precárias que condicionam a formação de criadouros. Oliveira (2012) diz: "Quando o Aedes aegypti encontra condições ideais para seu desenvolvimento e proliferação, ocorre uma grande infestação do mosquito".

Pedro Luiz Tauil (2002) ressalta que os objetivos do controle da dengue devem ser estabelecidos com base na sabedoria científica e técnicas disponíveis ${ }^{1}$. No país, há décadas, a Medicina Veterinária é reconhecida como uma profissão da área da Saúde. A presença do médico-veterinário (MV) na área é antiga, embora seu reconhecimento tenha se dado recentemente por meio da Resolução CNS no 38/1992 (AMORIM; CARNEIRO, 2005). Araújo (2013) destaca que a participação dos MV nas ações de combate da dengue ocorreu, oficialmente, em 1998.

A constituição de comitês e equipes de força-tarefa vem contando com a atuação direcionada dos MV. Essas delegações brasileiras, por meio da mobilização dos Departamentos de Vigilância Epidemiológica, são formadas para controlar e prevenir a dengue, reduzir o número de enfermos e proteger a população. Esses Departamentos de Vigilância Epidemiológica (VE) são subordinados às Secretarias Municipais de Saúde, as quais, por sua vez, respondem, diretamente, às regulamentações estaduais e federais. Essa integração intersetorial projeta uma união multiprofissional e foi favorecida pela chegada à história

\footnotetext{
1 Dr. Pedro Luiz Tauil trabalha na área de Medicina Social da Faculdade de Medicina na Universidade de Brasília.
}

da Medicina Contemporânea da expressão Saúde Única², significando uma área específica de atuação profissional que engloba, simultaneamente, toda a sociedade, as zoonoses emergentes, arquitetura e urbanismo, segurança dos alimentos, biodefesa e biossegurança ${ }^{3}$, doenças nos seres humanos, nos animais domésticos e selvagens e, ainda, a preservação do meio ambiente.

\section{Sobre a função do médico-veterinário no combate às arboviroses}

A atuação dos profissionais MV engloba promoção da saúde humana, promoção da saúde e do bem-estar animal (BEA) e preservação do meio ambiente, conforme consta da Constituição Federal e na lei de criação da Medicina Veterinária. As competências do MV estão definidas nos arts. $5^{\circ}$ e $6^{\circ}$ da Lei Federal no 5.517/1968 (BRASIL, 1968). Quanto à Medicina Veterinária, especificamente, a importância da aplicação dessa área do conhecimento é uma forma de garantia da operacionalidade (UNITED STATES ARMY, 2004). A vigilância veterinária em saúde é entendida como a concatenação das ações que proporcionam conhecimento e identificação de mudanças nos fatores determinantes e condicionantes do meio ambiente que interferem na saúde humana, com a finalidade de identificar as medidas de prevenção, controle e minimização dos riscos ambientais associados às doenças e aos agravos à saúde. Oliveira Abreu (2013) ressalta que o MV é o maior responsável pela conscientização da população e, baseados nessa premissa, a OMS e a Organização Mundial de Saúde Animal (OIE) referenciam a atuação da Medicina Veterinária como uma das únicas profissões que trabalham com populações e não com indivíduos ${ }^{4}$.

Questionamentos recorrentes minam a evolução do tema do trabalho de controle da dengue feito com o apoio dos MV. Um exemplo de pergunta que pode surgir é: "Por que o médico-veterinário deve se envolver no programa de controle da dengue se os animais não são infectados pelo vírus da dengue?". Para responder, é necessário saber que, por exemplo, dentro do Centro de Controle de Zoonoses (CCZ - em algumas regiões do país, também chamado de Unidade de Vigilância de Zoonoses - UVZ) ${ }^{5}$

2 A criação do conceito de Saúde Única tem sido atribuída a Calvin W. Schwabe (19272006), médico-veterinário americano e considerado o idealizador da epidemiologia veterinária, segundo Lerner (2013).

3 “A biossegurança é o conjunto de ações voltadas para o controle e a minimização de riscos advindos da exposição, da manipulação e do uso de organismos vivos que podem causar efeitos adversos no homem, nos animais e no meio ambiente" (EXÉRCITO BRASILEIRO, 2003)

4 A estratégia de unificação da saúde foi promulgada por quatro organismos internacionais: a Organização das Nações Unidas para a Agricultura e Alimentação (FAO), a Organização Mundial de Saúde Animal (OIE), a Organização Mundial de Saúde (OMS) e a Fundação das Nações Unidas para a Infância (Unicef) (CRUZ, 2015).

5 A partir de 2014, com as Portarias MS n. 758/2014 e MS n. 1.138/2014, esses órgãos também podem ser denominados de "Unidades de Vigilância de Zoonoses" (UVZ). No 
de alguns municípios brasileiros, durante a passagem de um único dia, as pessoas são orientadas pelo MV acerca das relações entre agente-hospedeiro-ambiente, sendo, portanto, o médico-veterinário um relevante disseminador dos conhecimentos que podem proteger uma população contra a dengue, diminuindo a sua prevalência e sua incidência por meio de procedimentos para o controle do mosquito, preservação da saúde humana e do meio ambiente ${ }^{6}$.

No contato direto, pessoal ou não, as pessoas recebem orientações de cunho científico sobre a prevenção e para o controle de arboviroses ${ }^{7}$. Os procedimentos para diminuição da prevalência e da incidência de dengue se expandem para hábitos e costumes da sociedade, condições ambientais e cuidados pessoais. Nessa esfera é que as atuações dos médicos-veterinários são mais eficazes e eficientes. A OMS estabelece que tais orientações englobam questões de saúde, meio ambiente e devem procurar a participação ativa da comunidade em estratégias como a "Atenção Primária Ambiental - APA" e a "Municípios e Comunidades Saudáveis" (AMORIM; CARNEIRO, 2005).

Um outro exemplo de questionamento que contesta a participação de médico-veterinários no controle da dengue vem a seguir: "Não poderia o médico-veterinário estar exercendo uma função que é a priori destinada aos médicos de humanos?". Aqui, o esclarecimento diz respeito à necessidade de ciência sobre o mesmo esforço para a preservação da população humana, o qual deve ser feito pelo MV, além do médico humano, que preservará a saúde. $\mathrm{O}$ médico-veterinário previne o estabelecimento de condições que afetem a higidez humana, antes que a doença se manifeste. Antes de mais nada, seu, trabalho é multidisciplinar, multissetorial e inclui os maiores recursos de sua formação: o aconselhamento da população e a influência na sociedade. Portanto, quem atua como MV deve desenvolver suas capacidades profissionais, teóricas e práticas de forma fácil e útil, ampliando suas bases científicas, de modo a transcender as competências de uma ou de outra profissão.

entanto, não se pode afirmar, exclusivamente, que os serviços de controle de zoonoses passaram a ser denominados de "Unidades de Vigilância de Zoonoses" (UVZ). A Portaria MS n. 758/2014 incluiu na Tabela de Tipos de Estabelecimentos de Saúde do SCNES o Subtipo 01 - Unidade de Vigilância de Zoonoses, e a Portaria MS n. 1.138/2014 define as ações e os serviços de saúde voltados para vigilância, prevenção e controle de zoonoses e de acidentes causados por animais peçonhentos e venenosos, de relevância para a saúde pública.

6 Vide Art $6^{\circ}$ da Lei Federal n. 5.517/1968 que diz: “Constitui, ainda, competência do médico-veterinário o exercício de atividades ou funções públicas e particulares, relacionadas com: .... estudo e a aplicação de medidas de saúde pública no tocante às doenças de animais transmissiveis ao homem".

7 Arboviroses são doenças virais transmitidas por artrópodes hematófagos (JOURDAIN et al., 2015)
Outra questão que pode vir sequencialmente à mente do médico-veterinário é: "Por que eu não devo me preocupar também com a febre amarela urbana?". Essas e outras perguntas, de fato, podem pairar na cabeça de todos que raciocinam sobre o tema e basta refletir um instante. Não se trata de escolher "uma ou outra profissão" ou optar entre "uma ou outra doença". Para exercer a promoção da saúde e a prevenção de doenças e agravos, e, adicionalmente, intervir em reservatórios de doenças, é necessário o conjunto de saberes dos diversos profissionais que, eventualmente, se apresentem na Secretaria de Saúde dos munícipios brasileiros, por exemplo.

Como foi definido em registros oficiais do Estado Maior do Exército, "a Medicina Veterinária é uma especialidade estratégica no campo da saúde, uma vez que é vocacionada para as ações de defesa biológica, saúde pública, vigilância sanitária e gestão ambiental" (INTERNATIONAL COMMITTEE OF MILITARY MEDICINE, 2009).

Sugere-se, então, que as instâncias propositivas e consultivas sejam aplicadas quando houver a necessidade de serem ultrapassadas barreiras tecnicamente estabelecidas no exercício da profissão médica veterinária. A atuação do MV em saúde pública encontra respaldo em resoluções do CFMV e outros dispositivos legais, sem que surjam barreiras para a atuação profissional. A investigação em documentos, artigos, legislação, resoluções e obras literárias assume um papel importante na tomada de decisão sobre o que o MV deve fazer ou não. Isso serve para designar a pesquisa epidemiológica e laboratorial e da mesma maneira pode ajudar na criação de programas inovadores, sobretudo na área da Vigilância em Saúde e no aperfeiçoamento de políticas públicas para o país.

A ação médica veterinária a favor de políticas públicas não é estimulada dentro do ambiente acadêmico e nem são desenvolvidas as habilidades para que os médicos-veterinários trabalhem coletivamente, juntos aos médicos, nas universidades. Como apontaram os pesquisadores, é notória a baixa carga horária das disciplinas das áreas social e humana, as quais representam apenas $4,79 \%$ da grade curricular nos cursos públicos e 7,70\% nos cursos privados (CRUZ, 2015; SOUZA, 2010). Em São Paulo, a média total de horas dedicadas à disciplina de Medicina Veterinária preventiva é de apenas $8,71 \%$ (CRUZ, 2015). Após a graduação, fica a critério do profissional MV a busca do seu aprimoramento e da ampliação das suas próprias competências para atuar no caso da dengue.

O caminho a ser seguido idealmente pode vir a ser o da pesquisa científica e experimentação, por meio de buscas 
avançadas, consultas, exposições e proposições para que os contextos da Medicina humana e da Medicina Veterinária sejam desenvolvidos conjuntamente e fortalecidos. A transferência, transporte ou "traslado" de conhecimento clínico ou terapêutico pode ocorrer. Os MV têm a competência de atuar nas condições de risco do meio ambiente, na seleção de produtos químicos a serem indicados no tratamento de focos de Aedes e em pesquisas de alterações de genomas do vetor. Os médicos humanos têm a competência de tratar dos doentes e para atuar junto às pessoas, prevenindo a doença. Em alguns momentos as competências médicas são comuns, como nas áreas de pesquisa das vacinas e nos programas de Educação em Saúde.

Os limites entre as duas Medicinas vão se tornando cada vez mais tênues. Na verdade, as competências dos dois profissionais não se chocam, mas se complementam. A Medicina Veterinária insere-se como ponto de ancoragem de conhecimentos (SOARES et al., 2015) e o MV tem como responsabilidade a realização das inspeções e avaliações do saneamento da área onde ocorre a dengue, compreendendo, então, o conjunto de informações de valor estratégico direta ou indiretamente relacionadas à saúde e ao campo da Medicina Veterinária.

$\mathrm{Na}$ abordagem das competências do MV, vale destacar o trabalho de monitoramento e controle da qualidade e do armazenamento dos recursos hídricos. No caso dos recursos hídricos, é o MV que pode aperfeiçoar sistemas de filtragem contra poluentes físicos e químicos. Além disso, o médico-veterinário conhece a temperatura, salinidade e $\mathrm{pH}$ da água que condicionam o crescimento de parasitas. Contemplando essa conjuntura, outros desafios biológicos encontrados em situações de risco produzem, com a interpretação dos MV, informações interessantes, como a relação entre os casos de infecção e a alta pluviosidade (SILVA et al., 2014).

Enfoca-se a ampla gama de conhecimentos de epidemiologia que os MV detêm e que cabem à chamada vigilância entomológica. Envolvendo profissionais de diversas áreas, essa vigilância inclui medidas de detecção de focos de reprodução de artrópodes, ou seja, pontos de proliferação dos vetores. A vigilância entomológica pode ser entendida como a contínua observação e avaliação de informações originadas das características biológicas e ecológicas dos vetores que proporcionam o conhecimento para detecção de qualquer mudança no perfil de transmissão das doenças (GOMES, 2002). Especificamente, para a dengue, a vigilância aborda dados sobre a domiciliação, dispersão, repasto e reprodução do Aedes, além da competência e capacidade vetorial (DONALÍSIO; GLASSER, 2002).

O MV recomenda medidas preventivas e de controle dos riscos biológicos, mediante a coleta sistematizada de dados e a consolidação no Sistema de Informação da Vigilância Ambiental em Saúde (SINVAS). As ações multissetoriais englobam a pesquisa em ovitrampas com posterior identificação das espécies (BRASIL, MINISTÉRIO DA SAÚDE, 2008). Para completar, a colaboração com agências brasileiras da Saúde, como institutos de pesquisa, dos quais são exemplos a Fundação Oswaldo Cruz (Fiocruz) e a Superintendência do Controle de Endemias (SUCEN), e com laboratórios credenciados deve ocorrer pelo intercâmbio de conhecimentos entre os MV, médicos, biólogos e pesquisadores.

O assunto da dengue aborda, contudo, ainda outro ponto de vista da integralização. Além do que já foi dito, é interessante analisar a atuação em conjunto dos MV e de outros profissionais, levando ao exercício da Medicina Única. Esse termo foi modernamente consagrado na comunidade científica internacional pelo Comitê de Necessidade de Pesquisa em Ciências Veterinárias do Conselho Estadunidense de Pesquisa, o National Research Council - US; Committee on the National Needs for Research in Veterinary Science (ROSOL et al., 2009). No Brasil, desde 1977, a Medicina única já aparece como premissa, merecendo enfoque no contexto ideológico, com as palavras de Herval Pina Ribeiro (1977): “[...] é a Medicina possível de ser exercida, dentro de condições objetivas de trabalho e de uma realidade mais abrangente $[. .$.$] ]". No que concerne ao trabalho do médico-$ -veterinário com ações preventivas, esse conceito se adequa, podendo ser disseminado dentro do grupo social dos profissionais de Medicina.

\section{Conclusão}

São ações e atribuições ligadas à Medicina Veterinária: analisar, propor, assessorar, cooperar e monitorar os indicadores epidemiológicos e entomológicos relacionados à prevenção da dengue. Os médicos-veterinários devem ser motivados para que sua formação, capacitação e habilitação em Medicina Veterinária os levem à modificação do panorama sanitário brasileiro e à valorização da sua profissão. Com a realização de estudos sobre epidemiologia, zoonoses e Medicina Veterinária preventiva, o médico-veterinário poderá contribuir para a transformação das condições das endemias de dengue, chikungunya e zika e também mudará a atual sensação de insuficiente inclusão profissional no contexto da saúde única. Mas para que ocorra tal transformação, é necessária a promoção de uma maior interação entre médicos, biólogos, médicos-veterinários, químicos e engenheiros químicos, geólogos e educadores, dentre outros, para benefício e sucesso do Programa de Controle da Dengue e da promoção dos conceitos de Medicina Única. (1) 


\section{Referências}

AMORIM, A. M., CARNEIRO, F. F. A participação do médico-veterinário nas questões ambientais, 2005. Disponivel em: <http://www.famev.ufu.br/documentos>. Acesso em: 15 de jun. 2016.

ARAÚJO, M. M. Inserção do médico-veterinário no núcleo de apoio à saúde da família: estudos, perspectivas e propostas. 2013. 83 p. Tese (doutorado) - Faculdade de Ciências Agrárias e Veterinárias, Universidade Estadual Paulista Júlio de Mesquita Filho , Jaboticabal, 2013.

BHATT, S.; GETHING, P. W.; BRADY, O. J.; MESSINA, J. P.; FARLOW, A. W.; MOYES C. L.; DRAKE, J. M.; BROWNSTEIN, J. S.; HOEN, A. G.; SANKOH, O.; MYERS, M. F. GEORGE, D. B.; JAENISCH, T.; WINT, G. R. W.; SIMMONS, C. P.; SCOTT, T. W.; FARRAR, J. J.; HAY, S. I. The global distribution and burden of dengue. Nature, Londres, n. 496, p. 504-507, abr. 2013

BRASIL. Lei n. 5.517, de 23 de outubro de 1968. Dispõe sobre o exercício da profissão de médico-veterinário e cria os Conselhos Federal e Regionais de Medicina Veterinária. Disponível em: <http://www.crmvrj.com.br/new/ilegislacao/texto/lei5517.htm l>. Acesso em: 15 jun. 2016

Ministério da Saúde. Portaria n. 758, de 26 de agosto de 2014. Inclui subtipo na tabela de tipos de estabelecimentos de saúde do SCNES. Diário Oficial da União Poder Executivo, Brasília, DF, 2014. Disponível em: <http://bvsms.saude.gov.br/bvs/ saudelegis/sas/2014/prt0758_26_08_2014.html l>. Acessoem: 24 out. 2016.

. Avaliação de armadilhas para a vigilância entomológica de Aedes aegypt com vistas à elaboração de novos índices de infestação, 2008. Disponível em <http:// www.saude.gov.br>. Acesso em: 20 jan. 2016.

CRUZ, C. A. O ensino da saúde pública veterinária nos cursos de graduação em Medicina Veterinária da Região Sudeste do Brasil. 2015. Dissertação (Mestrado em Medicina Veterinária Preventiva). Universidade Estadual Paulista, Jaboticabal, 2015.

DAHER, M. J. E.; BARRETO, B. T. B.; CARVALHO, S. C. Dengue: aplicação do protocolo de atendimento pelos enfermeiros. Revista de Enfermagem da UFSM, Santa Maria, v. 3, n. 3, set.-dez., p. 440-448, 2013.

DONALÍSIO, M. R.; GLASSER, C. M. Vigilância entomológica e controle de vetores do dengue. Rev. Bras. Epidemiol, São Paulo, v. 5, n. 3, p. 259-271, 2002.

EXÉRCITO BRASILEIRO. Estado-Maior do Exército. Logística militar terrestre. 2. ed Brasília, 2003.

GOMES, A. C. Vigilância Entomológica. Informe Epidemiológico do SUS, Brasília, v. 11 n. 2, p. 79-90, 2002.

INTERNATIONAL COMMITTEE OF MILITARY MEDICINE. Statutes of the International Committee of Military Medicine. Bruxelas, 2009.

JOURDAIN, F.; ROIZ, D.; PERRIN, Y.; GRUCKER, K.; SIMARD, F.; PAUPY, C. Facteurs entomologiques d'émergence des arboviruses. Transfusion Clinique et Biologique, Montpellier, v. 22, n. 3, ago., p. 101-106, 2015.

LACAZ, C. S.; BARUZZI, R. G.; SIQUEIRA JR., W. Introdução à geografia médica do Brasil. São Paulo: Edgard Blucher, 1972

LERNER, H. The philosophical roots of the 'One Medicine' movement: an analysis of some relevant ideas by Rudolf Virchow and Calvin Schwabe with their modern implications. Studia Philosophica Estonica, University of Tartu, Estonia, v. 6, n. 2, p. 97-109, 2013.

SILVA, R. M.; SILVA, A. M.; CHAVES, J.J.S Vulnerabilidade espacial da dengue e sua relação com a variabilidade termopluviométrica em João Pessoa-PB. Hygea, Uberlândia, v. 10, n. $18,2014$.

MATOS, A. Fiocruz apresenta DengueTech em Congresso Nacional de Saúde. Agência Fiocruz de Notícias. Disponível em: <https://agencia.fiocruz.br/fiocruz-apresentadenguetech-em-congresso-nacional-de-saude>. Acesso em: 15 jun. 2016.
OLIVEIRA, E. S. Formação inicial e continuada em agente de combate a endemias. Instituto Federal do Paraná, Curitiba, versão 1, Unidade 4, p. 1-29, 2012.

OLIVEIRA ABREU, S. R. A Medicina Veterinária na saúde coletiva. Conselho Regional de Medicina Veterinária do Alagoas. Disponível em:< http://www.crmv-al.org.br/site/ mostraconteudo.aspx?c=9>. Acesso em: 6 de maio 2016 .

PESSOA, S. B. Ensaios médico-sociais. São Paulo: Guanabara-Koogan, 1960

RIBEIRO, H. P. Em busca de uma Medicina ideal. Jornal Brasileiro de Pneumologia, São Paulo, v. 3, n. 2, p. 7, 1977.

ROSOL, T. J.; MOORE, R. M.; SAVILLE, W. J. A.; OGLESBEE, M. J; RUSH, L. J.; MATHES, L. E.; LAIRMORE, M. D. The Need for Veterinarians in Biomedical Research. Journal of Veterinary Medical Education, Toronto, v. 36, n. 1, p. 70-75, 2009.

SANTOS, F. O. Geografia médica ou geografia da saúde? Uma reflexão. Caderno Prudentino de Geografia, Presidente Prudente, v. 1, n. 32, jan..-jun., p. 41-51, 2010.

SOARES, O. A. B.; LIMA, J. R. P. A.; CAMPOS, C. H. C.; BARROS, R. S. A Medicina Veterinária militar brasileira em operações de paz: experiências na missão da Organização das Nações Unidas para estabilização do Haiti. Coleção Meira Mattos, Rio de Janeiro, v. 7, n. 29, p. 121-129, 2013.

SOUZA, P. C. A.; AMÓRA, S. S. A.; FIGUEIREDO NETO, A. B.; VALLANDRO, M. J.; LUCENA, F. L.; ANJOS, C. B.; PEREIRA, L.R.M. Ensino em saúde pública nas escolas de Medicina Veterinária do Brasil. Revista CFMV, Brasília, n. 51, p.16-22, 2010.

TAUIL, P. L. Urbanização e ecologia do dengue. Cadernos de Saúde Pública, Rio de Janeiro, v. 17, p. 99-102, 2001. Suplemento.

. Aspectos críticos do controle da dengue no Brasil. Cadernos de Saúde Pública, Rio de Janeiro, v. 18, n. 3, p. 867-871, maio-jun. 2002.

UNITED STATES ARMY. Veterinary service: tactics, technics and procedures (FM 4-02.18), [Washington, DC]: Headquarters, Department of the Army, 2004. 